\title{
Effect of Quenching Condition on Corrosion Behavior of 6063 Al Alloy
}

\author{
Chunlin $\mathrm{He}^{\mathrm{a}}$, Rui Li, Xiaodan Meng, Shuai Lü, Leipeng Xie, Guofeng Ma,
} Jianming Wang

Liaoning Provincial Key Laboratory of Advanced Materials, Shenyang University, Shenyang 110044, China

${ }^{a}$ Ccllhhe@126.com

Keywords: $6063 \mathrm{Al}$, quenching rate, corrosion behavior

Abstract. The effect of quenching condition such as air cooled (AC) and water quenched (WQ) treatment on the corrosion behavior of $6063 \mathrm{Al}$ alloy was investigated by optical microscope, field emission scanning electron microscope and electrochemical work station. The experimental results showed that the corrosion resistance of the AC $6063 \mathrm{Al}$ alloy was much worse than that of the WQ one, and the corrosion form of the AC sample was intergranular corrosion (IGC) and pitting whereas only pitting was found on the WQ alloy. Slow quenching after solution heat treatment caused grain boundary precipitation $\mathrm{Mg}_{2} \mathrm{Si}$, introducing IGC susceptibility. The corrosion mechanism of pitting was contributed to galvanic corrosion between coarse impurity phase particles (Al-Fe-Si) and matrix $\mathrm{Al}$, and IGC resulted from galvanic corrosion between grain boundary precipitates and matrix Al.

\section{Introduction}

$6 \times \times \times$ series aluminum alloys are extensively used in architectural, automotive and marine applications owing to favorable strength-to-weight ratio, compliance to surface treatment and good corrosion resistance. However, these alloys may sometimes develop susceptibility to intergranular corrosion (IGC) as a result of unfavorable heat treatment [1, 2]. In the $6 \times \times \times$ series Al-Mg-Si alloys IGC has been attributed to the anodic dissolution of the hardening phase $\mathrm{Mg}_{2} \mathrm{Si}$ [3]. The IGC susceptibility of heat treatable aluminum alloys is mainly related to the quenching or/and ageing treatment after solution annealing and small changes in these routines can cause significant changes in corrosion resistance [1, 4]. Slow quenching and ageing treatment after solution heat treatment is known to cause grain boundary precipitation [5], which could introduce IGC susceptibility [4]. Compared with the underaged and overaged, the T6 treated Al-Mg-Si alloy containing $\mathrm{Cu}$ showed much strong susceptibility to IGC [6].

In the present paper, the $6063 \mathrm{Al}$ alloy was solution heat treated and then quenched in air and cold water, which represented quick and slow quenching condition, respectively. The objective is therefore to investigate the effect of quenching rate on IGC susceptibility of $6063 \mathrm{Al}$ alloy.

\section{Materials and Method}

The investigated material was an extrusion rod of $6063 \mathrm{Al}$ alloy, its chemical composition was listed in Table 1. Samples of diameter $1.2 \mathrm{~cm}$ and high $1.0 \mathrm{~cm}$ were solution heat treated for $40 \mathrm{~min}$ at $520{ }^{\circ} \mathrm{C}$ and then quenched in room temperature water and air immediately, respectively.

Electrochemical measurements were made at $25{ }^{\circ} \mathrm{C}$ in a three-electrode cell containing 3.5\% $\mathrm{NaCl}$ aqueous solution with a PARSTAT 2273 advanced electrochemical system. A saturated 
calomel electrode was used as the reference electrode, and the counter electrode was graphite. Before electrochemical measurements, the samples were immersed in solution until a steady open circuit potential was recorded. Potentiodynamic polarization tests were carried out at a scanning rate of $0.332 \mathrm{mV} / \mathrm{s}$. Electrochemical impedance spectroscopy (EIS) was measured by perturbing the open circuit potential of the specimens with a $10 \mathrm{mV}$ ac signal with a frequency decreasing from $10^{5} \mathrm{~Hz}$ to $1 \mathrm{mHz}$. The specimens were covered with paraffin for electrical insulating except the surface for electrochemical measurements.

The morphology was observed by field emission scanning electron microscope (FE-SEM) with an energy dispersive X-ray spectroscopy (EDS) and optical microscope.

Table 1 Chemical composition of 6063 aluminum alloy (mass fraction, \%)

\begin{tabular}{ccccccccccc}
\hline $\mathrm{Mg}$ & $\mathrm{Si}$ & $\mathrm{Cu}$ & $\mathrm{Fe}$ & $\mathrm{Mn}$ & $\mathrm{Cr}$ & $\mathrm{Zn}$ & $\mathrm{Ti}$ & $\mathrm{Ce}$ & Others & $\mathrm{Al}$ \\
\hline $0.45-0.90$ & $0.2-0.6$ & 0.10 & 0.35 & 0.10 & 0.10 & 0.10 & 0.10 & 0.5 & 0.15 & Bal. \\
\hline
\end{tabular}

\section{Results and Discussion}

Fig. 1 presents the FE-SEM microstructure image of the $6063 \mathrm{Al}$ alloy, which clear shows that there are lots of white stick particles. EDS analysis result shows that these particles are composed of Al, $\mathrm{Fe}$ and $\mathrm{Si}$, they should be Al-Fe-Si phase such as $\beta$-Al ${ }_{5} \mathrm{FeSi}$. For 6063 aluminum alloy, slow quenching (for example, air cooling) after solution heat treatment can cause grain boundary precipitation of $\mathrm{Mg}_{2} \mathrm{Si}$ particles [7]. However, $\mathrm{Mg}_{2} \mathrm{Si}$ particles will not occur in the case of higher quenching rate such as water quenching.
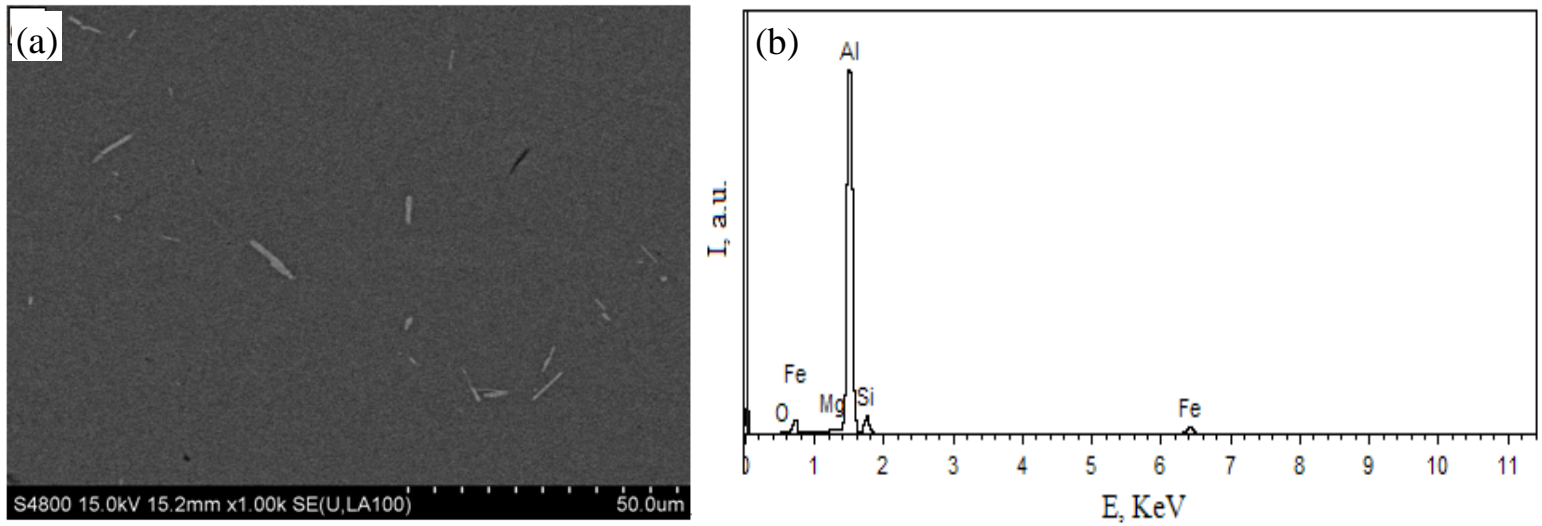

Fig.1 FE-SEM microstructure image (a) and EDS analysis result of the stick particles (b)

In order to evaluate the corrosion resistance of the alloy, EIS and polarization curve was measured. Fig. 2 shows the EIS curves of the AC and WQ $6063 \mathrm{Al}$ alloys in deaerated 3.5\% $\mathrm{NaCl}$ solution, which clear indicates that the former has a lower corrosion resistance.

Fig.3 presents potentiodynamic polarization curves of the AC and WQ $6063 \mathrm{Al}$ alloys in deaerated $3.5 \% \mathrm{NaCl}$ solution, and the relative electrochemical parameters calculated are shown in Table 3. It is clearly seen that a wide passivation region appeared for the AC sample while almost no passivation was found for the WQ one. The AC sample has a bigger corrosion current density ( $\left.\mathrm{I}_{\text {corr }}\right)$ and a much more negative corrosion potential $\left(\mathrm{E}_{\text {corr }}\right)$ than that of the WQ one, which indicates that the former possesses a much lower corrosion resistance. The corrosion resistance of the alloy is closely associated with its microstructure, which strongly depends on the quenching process after solution treatment. In the case of water quenching, because the dissolved hardening phase $\mathrm{Mg}_{2} \mathrm{Si}$ can not re-precipitate from the supersaturated solid solution, the alloy has a much higher corrosion potential and lower corrosion driving force, resulting in a much lower corrosion rate compared with 
the AC sample.

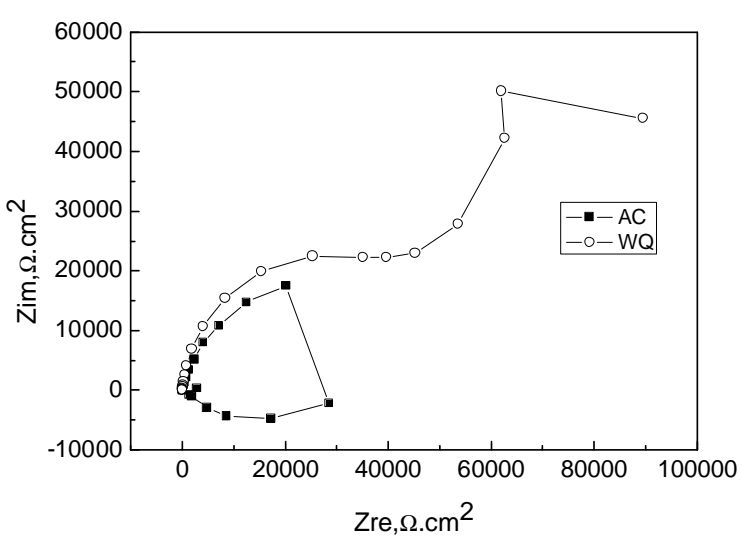

Fig. 2 EIS curves of $6063 \mathrm{Al}$ alloy in $3.5 \% \mathrm{NaCl}$ solution

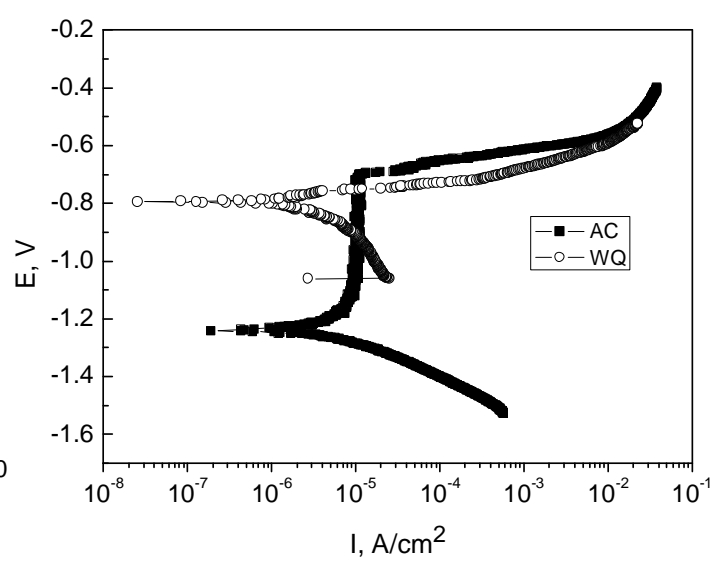

Fig. 3 Potentiodynamic polarization curves of $6063 \mathrm{Al}$ alloy in $3.5 \% \mathrm{NaCl}$ solution

Table 3 Electrochemical parameters obtained from Fig. 3

\begin{tabular}{cccc}
\hline Sample & $\mathrm{I}_{\text {corr }} /\left(\mu \mathrm{A} \cdot \mathrm{cm}^{-2}\right)$ & $\mathrm{E}_{\text {corr }} / \mathrm{V}$ & $\mathrm{E}_{\text {pit }} / \mathrm{V}$ \\
\hline $\mathrm{AC}$ & 2.39 & -1.240 & -0.687 \\
$\mathrm{WQ}$ & 1.34 & -0.794 & -0.737 \\
\hline
\end{tabular}
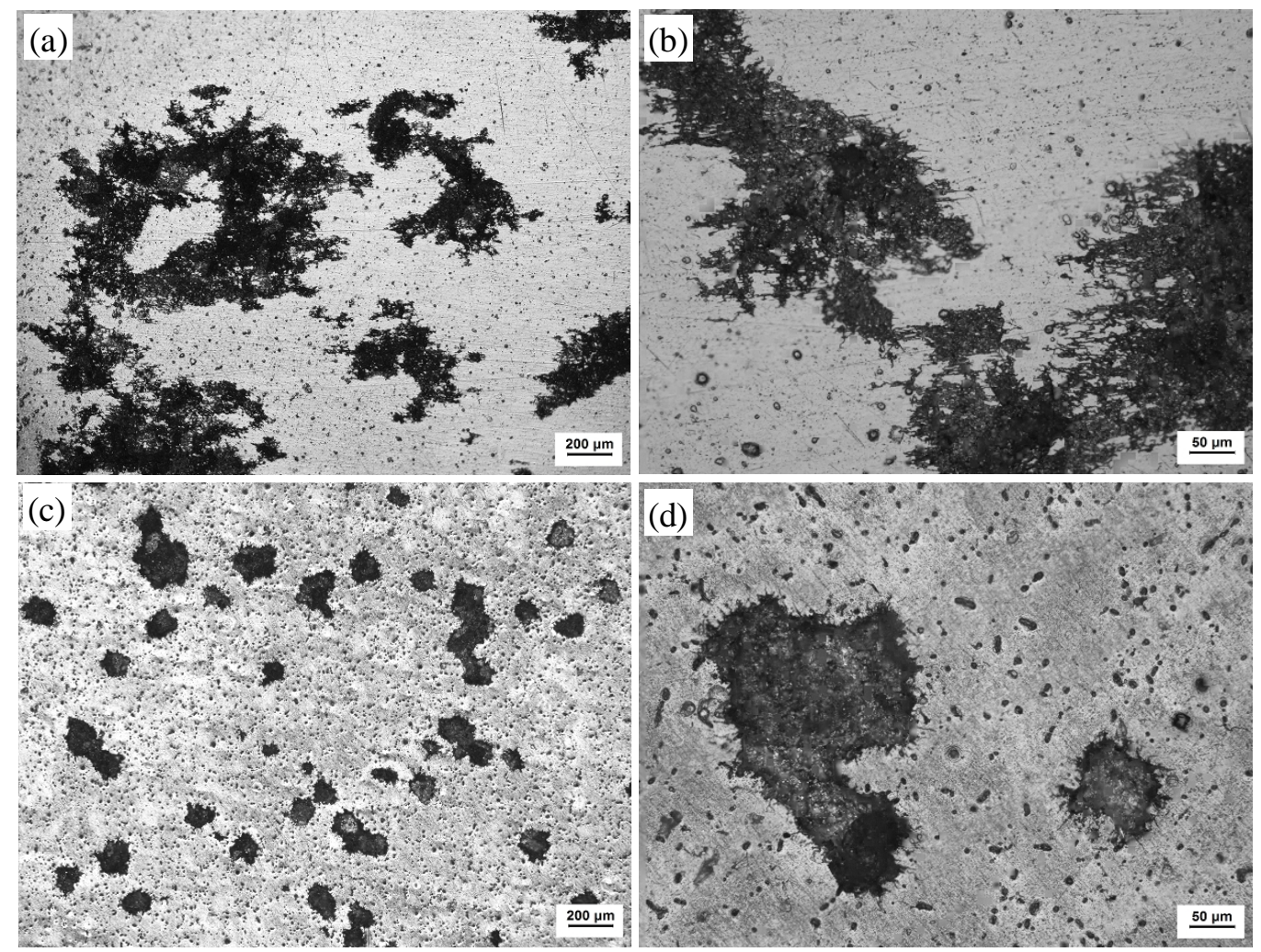

Fig.4 The corrosion morphologies of the AC (a, b) and WQ (c, d) $6063 \mathrm{Al}$ alloys

Fig. 4 presents the corrosion morphologies of air cooled and water quenched samples after polarization tests in $3.5 \% \mathrm{NaCl}$ solution, which showed that there appeared local corrosion. For the AC sample, the corrosion mode is local intergranular corrosion and pitting (Figs. 4a, b); however, only pitting was found on the WQ specimen (Figs. 4c, d). Slow quenching such as air cooled after solution heat treatment can cause grain boundary precipitation [5], which can introduce IGC susceptibility [4]. It is believed that the intergranular corrosion results from microgalvanic cell action at the grain boundary, related to grain boundary precipitates of $\mathrm{Mg}_{2} \mathrm{Si}$ formed during air 
cooled period. The $\mathrm{Mg}_{2} \mathrm{Si}$ particles are more active than the adjacent matrix $\mathrm{Al}$ [8], which can be dissolved during immersion in $\mathrm{NaCl}$ aqueous solution [3]. And the pitting is a result of galvanic corrosion between Al-Fe-Si particles and matrix Al. Herein Al-Fe-Si acts as cathode and the anode $\mathrm{Al}$ nearby is dissolved, leaving small corrosion pits (Fig.4). Because the cooling rate from solution temperature to room temperature water is so fast that there is not enough time for $\mathrm{Mg}_{2} \mathrm{Si}$ particles to precipitate on the grain boundary, pitting is the only corrosion form for the WQ sample (Figs. 4c-d).

\section{Conclusions}

The effect of quenching rate such as AC and WQ treatment on the corrosion behavior of $6063 \mathrm{Al}$ alloy was investigated by optical microscope, FE-SEM and electrochemical technology. The experimental results showed that the corrosion resistance strongly depended on quenching rate. The AC sample has a bigger corrosion current density and a much more negative corrosion potential than that of the WQ one, showing its corrosion resistance was much worse than that of the latter. The corrosion form of the AC sample was intergranular corrosion and pitting whereas only pitting was found on the WQ alloy. Slow quenching after solution heat treatment caused grain boundary precipitation $\mathrm{Mg}_{2} \mathrm{Si}$, which could introduce IGC susceptibility. The corrosion mechanism of pitting was contributed to galvanic corrosion between coarse impurity phase particles (Al-Fe-Si) and matrix Al while IGC resulted from galvanic corrosion between $\mathrm{Mg}_{2} \mathrm{Si}$ and matrix $\mathrm{Al}$.

\section{Acknowledgements}

This work was supported by Program for Liaoning Excellent Talents in University (LR2013054), the Project-sponsored by SRF for ROCS, SEM and the National Natural Science Foundation (51171118) of China.

\section{References}

[1] G. Svenningsen, M.H. Larsen, J.C. Walmsley, J.H. Nordlien and K. Nisancioglu: Corros. Sci. Vol. 48 (2006), p. 1528

[2] D. Pan, Z. Wang, H. Li and Z. Zheng: The Chinese Journal of Nonferrous Metals Vol. 20 (2010), p. 435

[3] J.R. Davis: Corrosion of Aluminum and Aluminum Alloys (ASM International, 1999).

[4] G. Svenningsen, M.H. Larsen, J.H. Nordlien and K. Nisancioglu: Corros. Sci. Vol. 48 (2006), p. 258

[5] D.A. Porter and K.E. Easterling: Phase Transformations in Metals and Alloys, 2rd ed. (Stanley Thornes Ltd., Cheltenham, UK 2000).

[6] L. He, Y. Chen, J. Cui, X. Sun, H. Guan and Z. Hu: Corros. Sci. Protect. Technol. Vol. 16(3) (2004), p. 129

[7] F.S. Pan and D.F. Zhang: Aluminum Alloys and Their Applications (Chemical Industrial Press, Beijing, China 2006).

[8] N. Birbilis and R.G. Buchheit: J. Electrochem. Soc. Vol. 152(4) (2005), p. B140 